\title{
Elaboració de materials didàctics de medi natural per a l'alumnat nouvingut
}

\author{
Núria Mingueza de la Villa \\ nminguez@xtec.cat
}

Presentació d'un material didàctic de Coneixement de Medi Natural, per a l'alumnat nouvingut de cicle mig d'Educació Primària, que està format per dossiers de treball amb molt de suport gràfic per a la seva comprensió $i$ uns exercicis de fàcil realització per facilitar el seu accés al currículum escolar de medi natural.

Paraules clau: nouvinguts, medi natural, educació primària

\section{EXPLICACIÓ DEL TEMA}

El tema del projecte és l'elaboració d'uns dossiers de treball per a l'alumnat nouvingut, amb els continguts de les unitats didàctiques de Medi Natural que s'estan treballant al centre.

Aquests materials didàctics corresponen al nivell curricular del cicle mitjà d'Educació Primària.

En els darrers anys les escoles han augmentat la seva població escolar amb l'arribada d'alumnes estrangers que desconeixen la nostra llengua. Molts d'ells són de parla no romànica i fins i tot tenen un altre alfabet.

Tots tenim la voluntat d'oferir una bona acollida a tot l'alumnat, tant tenint en compte la seva part emocional, com la part més centrada en els aprenentatges propis del medi escolar.

L'acollida dels nous alumnes és tasca de tota l'escola, però sovint necessitem eines per fer-ho més adequadament.

\subsection{Aquest treball parteix de l'observació d'una necessitat}

En les reunions de coordinació dels últims anys, a l'hora de programar els Plans Intensius dels alumnes nouvinguts, reiteradament sorgia la complexitat de treballar i d'avaluar l'àrea curricular de coneixement del medi social i natural.
Malgrat l'existència de les aules d'acollida on l'alumne nouvingut rep un suport a l'àrea de llengua, per reforçar l'aprenentatge del català, ens trobem que en referència a l'àrea de coneixement del medi no disposàvem de materials adaptats per poder treballar a l'aula ordinària.

Per això calia elaborar uns materials didàctics perquè aquests alumnes poguessin treballar a l'aula els mateixos continguts que la resta de companys.

Aquests materials estan fets a partir del llibre de text, ja que és el principal referent de treball a l'aula, a partir del qual surten la majoria d'activitats. És el material que tenen els seus companys i companyes de classe.

Així l'alumne se sentirà més integrat, ja que el seu treball es correspon completament amb el dels seus companys i companyes.

\subsection{Objectius i resultats proposats}

El principal objectiu és facilitar la integració de l'alumne a l'escola ja que aquest serà el primer medi social on es trobarà en la seva arribada al nou país.

Ens cal una organització inclusiva del grups de classe per aconseguir-ho. És bàsic que tots els alumnes independentment del seu origen puguin adquirir nous aprenentatges. 


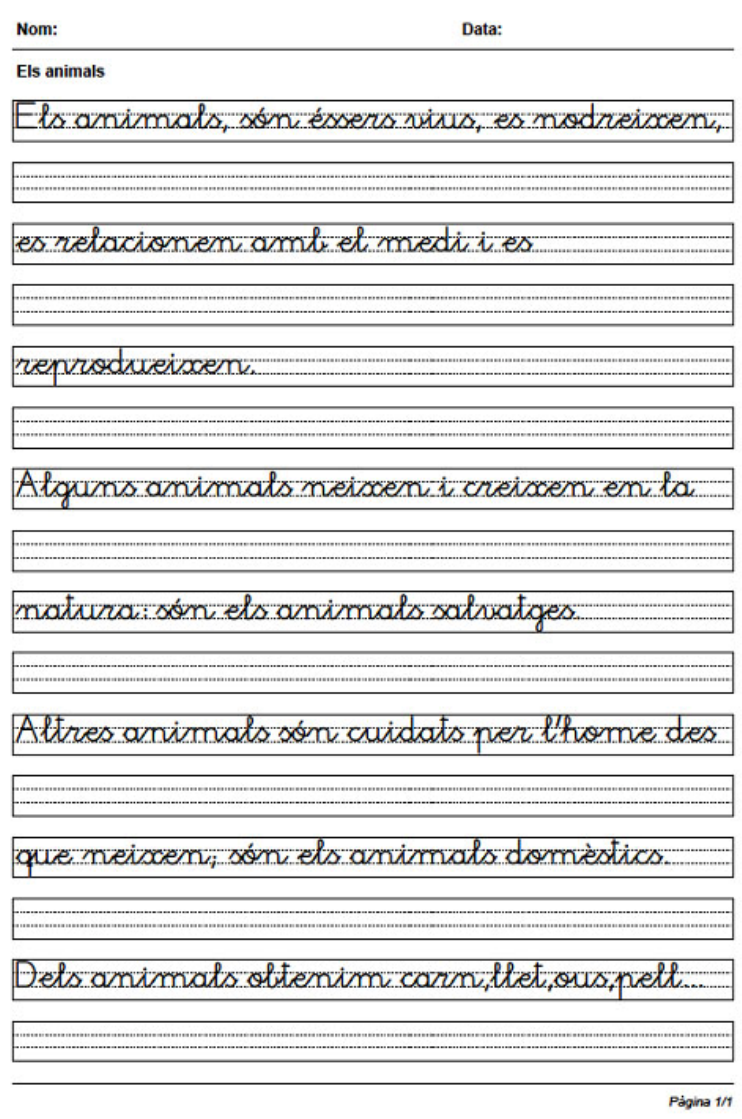

Els materials adaptats són una eina que el professor o professora pot utilitzar per aconseguir aquest objectius:

1) Millorar l'aprenentatge global de l'alumne o alumna

2) Afavorir i assegurar processos naturals d'autoestima

3) Facilitar l'assoliment del conceptes propis de l'àrea

4) Afavorir la integració fent que treballi els mateixos continguts que s'estan treballant a l'aula

Sovint ens trobem que les complexitats de la tasca diària dels professors no ens permeten dedicar tot el temps que voldríem a l'elaboració de materials.

Els materials de suport suposen una ajuda a la tasca del mestre. En el cas concret de l'assignatura de Coneixement del Medi havíem constatat que els materials adaptats de que disposàvem eren majoritàriament telemàtics. Com que només hi ha un ordinador per aula, aquest recurs ens resulta insuficient.

L'adaptació de les unitats del llibre de text resulta prou complexa i laboriosa pel tutor o tutora de l'aula, però en el cas dels alumnes nouvinguts resulta imprescindible, ja que es la única manera que els permet accedir als continguts del currículum treballant conjuntament amb els companys d'aula.

A part de la necessitat d'uns materials per als aprenentatges dels alumnes, per poder avaluar l'alumnat també calien uns instruments que permetessin treure conclusions de les seves observacions i valorar el progrés dels alumnes en aquesta àrea. Així doncs, a cada tema hi ha una proposta d'activitats d'avaluació.

\section{METODOLOGIA EMPRADA}

Tots els dossiers de treball tenen una estructura semblant i una mateixa tipologia de presentació del tema i de treball, ja que això centrarà molt més l'alumnat i li donarà seguretat un cop hagi treballat el primer dossier.

Estan seleccionats els continguts més bàsics $i$ els que necessitarà de cara a aprenentatges posteriors.

Alguns dels aspectes que s'han tingut en compte a l'hora d'elaborar aquests materials són:

- Molts d'aquests alumnes desconeixen el nostre alfabet i les grafies corresponents i els hi cal un treball més intensiu per anar-les adquirint. És per això que cada tema comença amb una pauta Montesori de cal-ligrafia. També trobarem exercicis de copiar, de resseguir, d'identificar paraules, de composar-les... per anar treballar l'alfabet.

- Aprofitant aquesta pauta s'introdueix un resum dels principals conceptes a treballar en aquest tema, i serà el primer contacte amb el vocabulari específic.

- Els títols de les unitats didàctiques i dels diferents apartats es corresponen amb els de la resta de companys. D'aquesta manera el treball de tots està connectat.

- Tot és molt gràfic: introduïm el vocabulari específic amb fotografies i dibuixos per tal de facilitar la comprensió.

- Els textos i les frases han de ser clares i senzilles.

- Les activitats han de facilitar al màxim el treball autònom de l'alumne i que pugui aplicar els coneixements que va adquirint malgrat no tenir prou coneixement de l'idioma; per tant, trobarem moltes activitats de relacionar, d'unir amb fletxes, dibuixar, omplir buits, completar paraules, subratllar, fer mots encreuats... 
- Hi ha activitats de diferent grau de dificultat per poder aplicar-les segons el grau de coneixement de l'idioma que tingui l'alumnat.

- Les activitats d'avaluació són en la mateixa línia que les del dossier de treball $i$ estan pensades per comprovar els progressos de cada alumne i cada alumna.

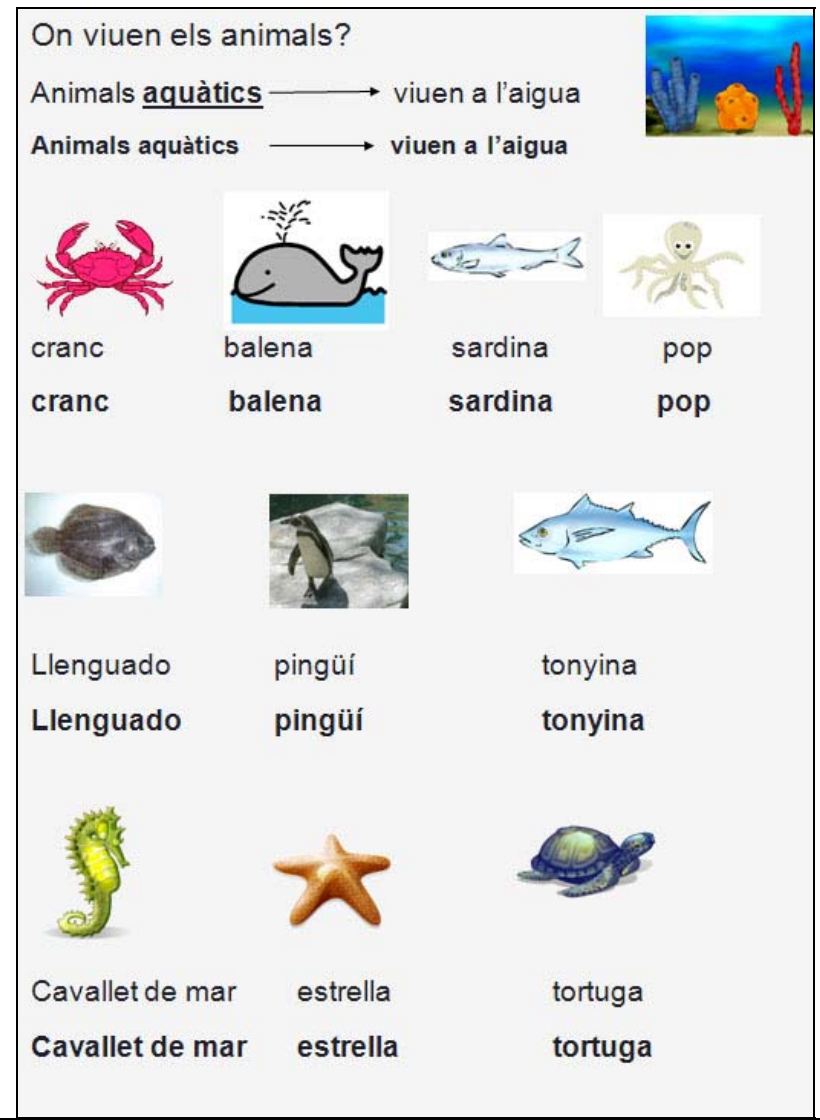

Figura 1. Exemple de presentació de vocabulari per poder fer les activitats sobre animals.

\section{RESULTATS OBTINGUTS}

\subsection{Presentació dels materials elaborats}

El material consta d'unes fitxes de treball adreçades a l'alumnat nouvingut dels centres de Educació Primària. El material està estructurat en quaderns: un per cada unitat temàtica. Cada dossier consta d'una síntesi molt breu dels conceptes fonamentals de cada tema i uns exercicis de fàcil realització proposats a partir dels textos resumits.

Per utilitzar el material s'han d'imprimir el fulls necessaris per a cada alumne.

D'un mateix tema en podem fer servir tot el dossier o només aquelles parts que ens interessin, ja que els exercicis es poden realitzar de manera independent. Cada full consta de les explicacions adients per poder treballar l'apartat concret que tracta.

Cada tema consta també d'una proposta d'avaluació, seguint el contingut a treballar en els quaderns.

Hem fet també una pàgina web on estan col.locats tots els dossiers, tant els corresponents a coneixement del medi natural com els de medi social. Els dossiers estan en format $p d f$. A la pàgina d'inici hi ha l'entrada a les unitats didàctiques de tercer i de quart d'Educació Primària. També hi estan penjades les orientacions didàctiques. Es pot consultar en aquesta adreça el material elaborat (consulta maig 2010).

Les unitats didàctiques corresponents a Coneixement del Medi Natural són les següents:

\section{Tercer d'Educació Primària:}

1) Éssers vius i éssers inerts

2) Els animals

3) Les plantes i les seves parts

4) Les plantes, éssers vius

5) Els sentits

6) L'aparell locomotor humà

7) Els materials

8) Elements de la natura

\section{Quart d'Educació Primària:}

1) El creixement

2) Els aliments

3) L'aparell digestiu

4) L'aparell respiratori

5) La nutrició de les plantes

6) Calor, llum i so

7) Les màquines

8) L'aire i la meteorologia

\subsection{Aplicació del treball amb els alumnes}

Després d'utilitzar aquests materials amb l'alumnat nouvingut s'ha vist que són uns materials molt útils que els permeten poder avançar en els seus aprenentatges.

Els permet avançar en els coneixements treballats de l'àrea de coneixement del medi natural i, alhora, avançar en l'ampliació del vocabulari i en el treball de la llengua.

Als alumnes se'ls nota molt contents amb la feina perquè la poden fer i això els motiva molt, sobretot a partir del segon dossier treballat, ja que al 
principi s'han de familiaritzar de mica en mica amb l'estructura dels materials.

Per a alguns alumnes encara resulta una mica difícil sobretot per als que porten molt poc temps aquí i per als que no coneixen encara l'alfabet.

En general poden fer les activitats amb prou autonomia.

Aquests materials s'han fet servir amb alumnes de l'aula de necessitats educatives especials, i els hi ha anat molt bé, ja que els facilita les tasques el fet de ser un material molt gràfic $i$ amb un llenguatge molt més senzill que el del llibre de text. A aquests alumnes els agradaven les feines i també es mostraven molt motivats en veure que ells sols podien fer-les i entenien el que feien.

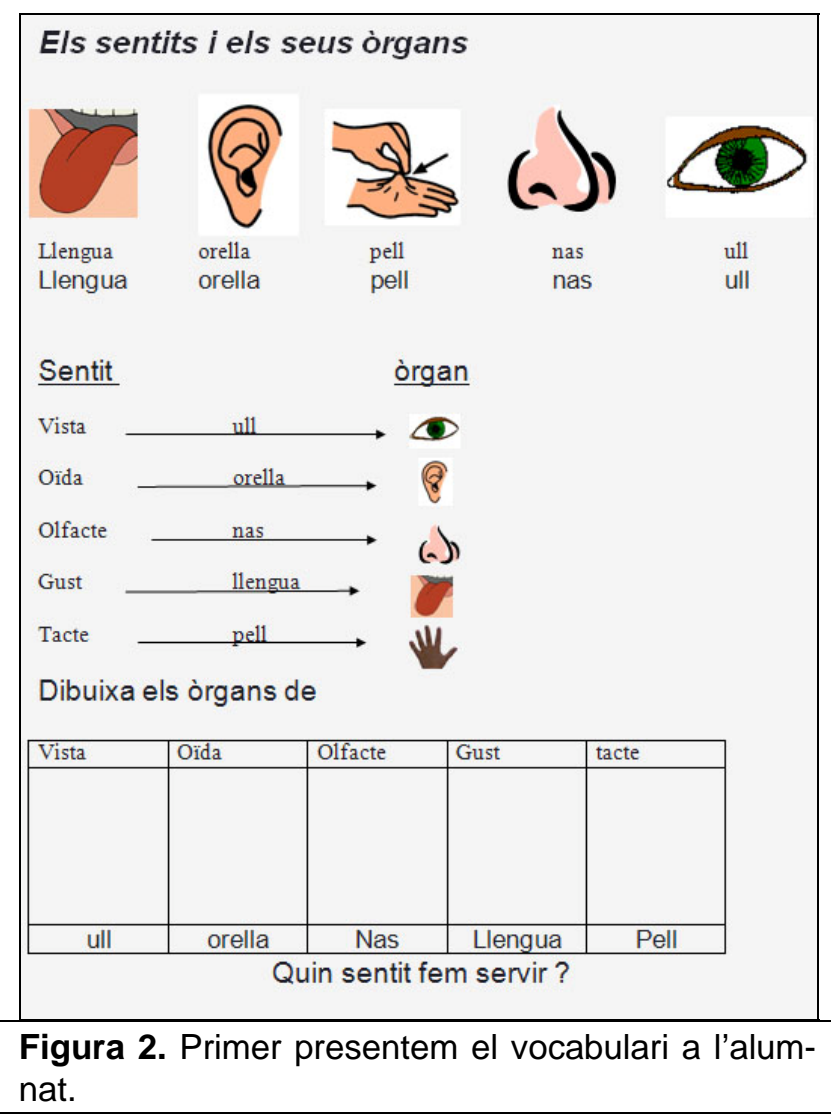

\section{BIBLIOGRAFIA}

\section{Referida a la integració escolar de l'alumnat nouvingut}

MONTON SALES, M. J. (1995). La integració de l'alumnat immigrant al centre escolar. Orientacions, propostes i experiències. Graó. Barcelona.

ALDAMIZ M. Del Mar i altres (2000). Com ens ho fem? Propostes per educar en la diversitat. Graó, Barcelona.

ZABALA, A. (1995). La pràctica educativa, com ensenyar. Graó, Barcelona.

\section{Referida als continguts curriculars de Medi Social}

CASAS, M. (1999). Les ciències Socials a l'ensenyament obligatori. Què ensenyar i per a què. III Jornades. Rosa Sensat, Barcelona.

TREPAT, Cristòfor A., RODRÍGUEZ, Asun, BATALLA, Elena, BATISTA, Montse i SUEZ, Carme. (2008). Medi natural, Social i Cultural. Cicle Mitjà 1-2. Barcanova. Barcelona.

Treball realitzat durant una llicència d'estudis del Departament d'Educació el curs 2008/09, forma part d'una tasca d'equip amb el projecte que presentà M. Nieves Gómez Blanco: Elaboració de materials didàctics de medi social per a l'alumnat nouvingut. 